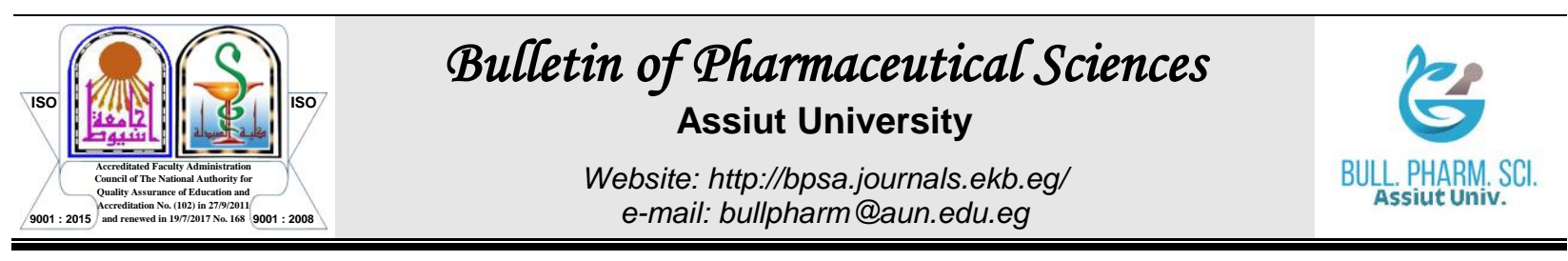

\title{
NEURAL STEM CELLS AS A PROMISING THERAPEUTIC APPROACH IN NEUROLOGICAL DISEASES
}

\author{
Rawaa S. Al-Mayyahi \\ Department of Clinical Laboratory Science, College of Pharmacy, University of Basrah, \\ Basrah, Iraq
}

The central nervous system lacks the ability to undergo neuronal regeneration. Neurological diseases such as neurotrauma and neurovascular diseases impact many people around the world. Neural stem cell-based treatment for neurological diseases limits clinical damage by providing and by regeneration local support for damaged and lost neural cells. Neural stem cells (NSCs) have a vital role in cell therapy as they can give rise to neurons or glial cells and repair neurological injuries. NSCs were able to secrete constitutively neuroprotective factors that have an important role in neurological repair. Moreover, upon transplantation, NSCs were shown capable of migration into lesioned sites and improved functional recovery after neurological diseases due to their important role in neurogenesis, immunomodulation, and brain plasticity. This review focuses on the roles of NSCs-based therapies in neurological diseases and summarise current advancements in NSC transplantation into rodent models of neurological disorders as well as shed the light on the progress of NSCs therapies in clinical trials.

\section{INTRODUCTION}

The central nervous system (CNS) lacks the ability to undergo neuronal regeneration. This has meant that there is currently no effective treatment to enhance CNS regeneration after injury and disease ${ }^{1}$. Neurological diseases such as neurotrauma, neuroinflammatory, and neurovascular diseases impact many people around the world ${ }^{2 \& 3}$. Cell therapy is an important approach that is commonly used to treat lost tissue and to enhance functional recovery following neurological disease/injury. Neuronal implantation promotes axon growth by: (1) replace lost neural cells (2) produce growth factors, such as brain derived neurotrophic factor (BDNF) to regrowth of disrupted neuronal axons and to promote the neurological repair ${ }^{4 \& 5}$. Several kinds of cells are widely used in regenerative medicine because they represent an effective treatment for several diseases. Neural stem cell (NSC) is one of the most important type of cell therapy, they play potential role in implantation and endogenous repair to treat different neurological diseases ${ }^{6}$. NSCs are defined as self-renewing, multipotent and unspecialised cells. They can be proliferated and differentiated into three specialised cells of CNS namely (neurons, astrocytes and oligodendrocytes) ${ }^{7-9}$. NSCs are found in two main regions called the subventricular zone (SVZ) and subgranular zone (SGZ) within the CNS. These two regions represent the sites of NSCs genesis in brain of adult mammalian ${ }^{10,11}$. The study of NSC biology has gave a new hope in the treatment of neurological disorder and traumatic nervous system lesion by replacing lost and damaged neural cells ${ }^{12-14}$. The neuroscientists investigate that NSCs (exogenous and endogenous) can be used in neurological diseases and injuries treatment. This type of cell can successfully reach the damage nervous tissue and differentiate to produce neurons and glia ${ }^{15 \& 16}$. Upon growth in culture, NSCs can be isolated 
from adult postnatal and embryonic, in many species. There are two systems widely used to increase and expand NSCs: 3-dimensional cultures (neurospheres) and 2-dimensional cultures (monolayers) ${ }^{17}$. This allows the generation of high quantities of cells and setting NSCs as a highly efficient source for neurological treatment. Moreover, upon transplantation, NSCs can migrate to the damaged site, presumably due to attraction by chemokines ${ }^{15}$. Several studies over the last decade showed improvement in various models of neurological disorders insults after NSCs transplantation in multiple animal models. NSCs transplantation often improved survival rates and declined cognitive function and pathology. Importantly, anti-inflammatory drugs used in different diseases treatment and also to reduce rejection and inflammation after implantation ${ }^{18}$. However, the exact mechanism by which NSCs exert their function remains unclear, as several mechanisms have been offered, such as induction of neurogenesis ${ }^{19}$, secretion various factors (e.g. BDNF, NT3 and NGF ${ }^{5 \& 20}$. This review summarises the recent progress using NSCs-based therapies for treatment various neurological diseases such as multiple sclerosis and stroke. Also, this article will discuss the limitations that hamper their treatment role and will review NSC-based therapy in several neurological diseases and how is this type of cell used in clinical trials.

\section{Characteristics and cultivation methods of neural stem cells}

The essential characteristics of NSCs are self-renewing, due to their ability to proliferate and generate new cells, multipotent, due to their ability to differentiate into neurons and glial cells in different regions. (3) Another extraordinary feature for clinical application, NSC migrates into the damaged regions ${ }^{21}$ (4) also, NSCs can improve the environment and enhance beneficial effects in the host by producing various neurotrophic factors and bioactive molecules ${ }^{7-9 \& 22}$. In neurological laboratory, NSC can culture by using two basic systems: i) 3-dimensional cultures (neurospheres). ii) 2-dimensional cultures (Monolayers). NSC of 3-D and 2-D cultures can be give rise to neurons and other glial cells (Figure 1) ${ }^{17}$.

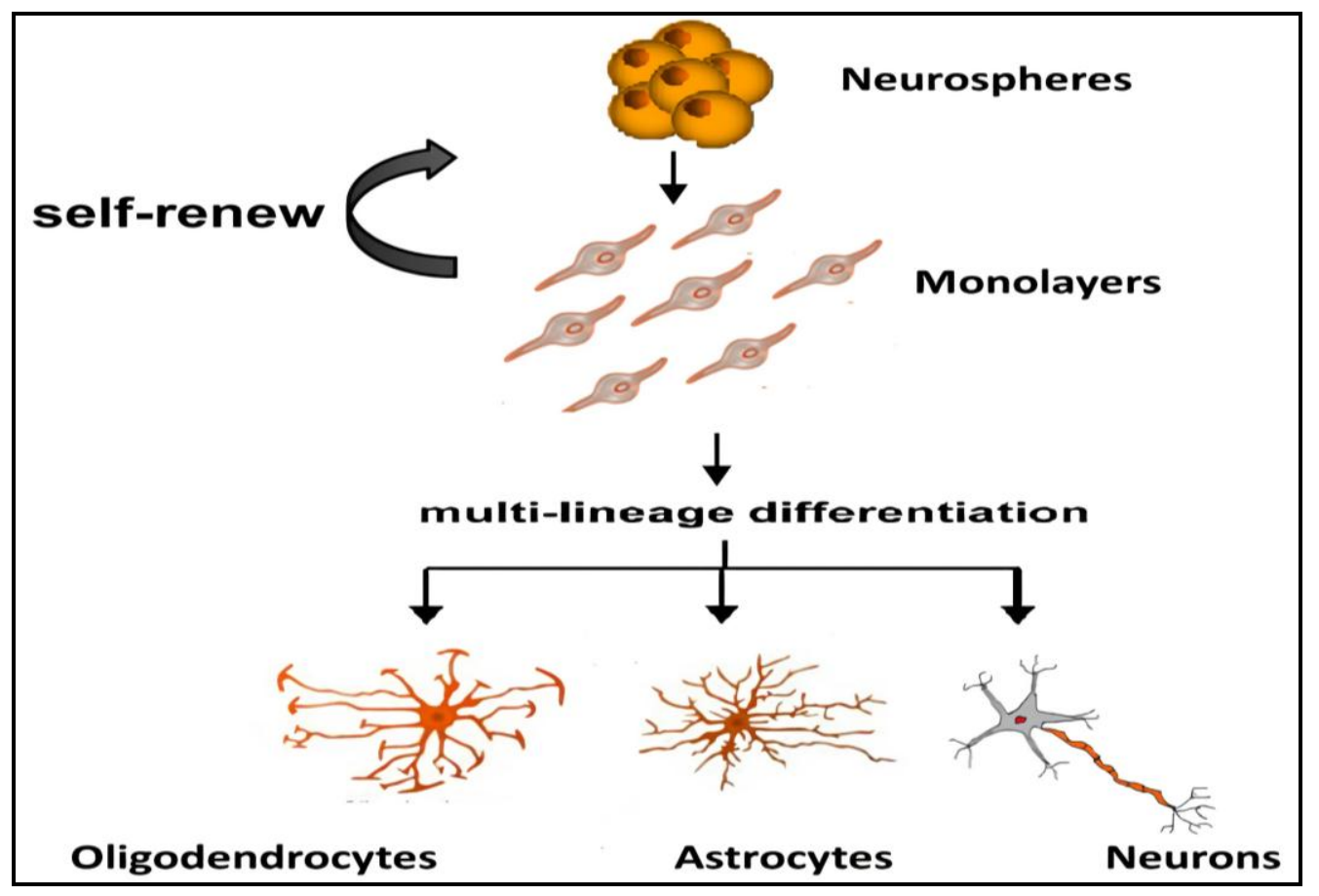

Fig. 1: The Characteristics and cultivation methods of NSCs. NSCs can be cultured as neurosphere in presence of growth factors, theses spheres passaged several times (self-renewal). Also, NSCs can be cultured as monolayers that adopt a typical bipolar morphology. The NSCs differentiate in the absence of mitogens and in the presence of serum to generate three different types of neural cells (multipotency). 


\section{Endogenous NSCs for neuroregenerative therapy}

An alternative approach for repair after neurological diseases is to promote endogenous NSCs in the CNS to produce the appropriate neurons. Several researchers are studying the treatment possibility of different neurological diseases/injures such as Parkinson's disease (PD), Spinal cord injury (SCI) and stroke using endogenous $\mathrm{NSC}^{23-26}$. It was observed that this type of cells can migrate to the damaged area and generate neuronal cells ${ }^{12 \& 27}$. The animals' experimental researches found an increase in proliferation and differentiation of neuronal cells in the SVZ region following a stroke, providing an evidence of the potential effects of NSCs in the neuroregenerative therapy ${ }^{28}$. Kaneko et al. found that endogenous NSC proliferation was increased and new neurons found in the neuronal damaged site in order to replace the lost cells after diseases ${ }^{29}$. Also, endogenous NSC enhances the impaired neurogenesis in acute or chronic neurological injuries $^{30}$. Most importantly, it was shown that the endogenous NSC can repair myelin sheath, also, it can be reached to the damaged site and produced the glial cells ${ }^{24}$. Interestingly, the use of endogenous NSC in neuroregenerative treatment avoids serious issues such as immunogenicity, ethical issues, and teratoma formation $^{29}$. However, several researches have suggested various limitations that are come with the use of this type of cell. For instance, endogenous NSC has limited ability to replace neural cell and they tend to be gliogenic more than neurogenic after injuries. Also, this type of cells cannot give rise to specific types of neural cell which consider as a serious issue in specific conditions treatment such as $\mathrm{PD}^{29}$.

\section{Neural stem cells transplantation ameliorate several neurological diseases in experimental models}

NSCs derived from animal and human foetal CNS, embryonic stem cells and induced pluripotent stem cell widely used in many preclinical studies. The interesting results showed a beneficial-functional effect of NSCs-based therapy for treatment of different neurological disorders. The CNS diseases characterised by neuronal or glial loss such as neurotrauma e.g traumatic brain injury (TBI) and SCI, multiple sclerosis (MS), stroke, Alzheimer's disease (AD), Huntington's disease (HD) and $\mathrm{PD}^{31}$. However, the regenerative capacity of the nervous system following injury and disease is limited unlike other tissues such as liver, skin and blood which have the capacity of selfrepair $^{32}$. The important target of neurosurgeons and neurologists is to find a way to treat and prevent negative effects of neurological diseases, especially neurodegenerative diseases.

There are two main therapeutic strategies to recover the neuron function following neurological problems: i) replacement: replacing the lost and damaged neural cells by cell transplantation and ii) neuroprotective: promoting the self-renewal mechanisms of the body to increase cell resistance against the surrounding toxicity ${ }^{33}$. Cell therapy offers a new hope for effective treatments for these diseases. Also, the progress in the biological studies of stem cell give a new hope to repair lost or damaged tissues following neurological lesions and diseases ${ }^{12-14 \& 33}$. There are many preclinical trials studies which show the positive neural structural change following NSC transplantation for example; it was observed that the transplanted NSCs induced the endogenous NSCs to migrate from SVZ region to replace the damaged tissue in rodent stroke model ${ }^{34}$. Interestingly, it was noted that the transplantation of NSCs turned out to increase endogenous cell proliferation and migration of the SVZ and dentate gyrus. The transplant NSCs can support tissue regeneration following stroke by modulating the inflammation, promoting the angiogenesis and producing neurotrophic factors ${ }^{35 \& 36}$. Also, Baker et al. demonstrated the positive effects of NSCs in a stroke pig model by increasing the migration of neuroblast, ameliorating inflammation by decreasing the number of microglia at the lesion border and promoting the differentiation into neurons and oligodendrocytes $^{37}$. They found out the treatment with NCSs promote neurogenesis and increase the expression of neurotrophic factors such as BDNF and NTF3 which are associated with neurons protection ${ }^{38}$. The NSCs therapy may also have advantageous effects in PD where dopaminergic neurons are lost through generation of dopamine neurons and it was 
found that the treatment with NSCs promote functional recovery in PD monkey and rat models by producing this type of neuron ${ }^{39 \& 40}$. Indeed, in animal model of $\mathrm{HD}$, various positive effects were reported following transplanted NSCs.

HD involves the degeneration of projection neurons. Recent studies of the R6/2 in the mouse brain of HD have shown an improvement in motor and cognitive functions following human NSCs transplantation ${ }^{41}$. Also, they were showed that transplanted NSCs in Huntington's animal model can improve the functional recovery by reducing cellular damage and promoting differentiation of NSCs into glial cells and neurons ${ }^{42}$. Amyotrophic lateral sclerosis (ALS) is a debilitating disease characterised by progressive decline in muscle functionality and poor prognosis due to degeneration of motor neurones ${ }^{43}$. It has been observed that innovative therapy using NSCs can induce endogenous NSCs to proliferate and repair damaged neural cells of ALS. Also, it was found that human NSCs implanted into a mouse model of ALS can be generated astrocytes and release growth factors in spinal $\operatorname{cord}^{44}$. Further, NSC transplantations offer a great therapy for SCI regeneration. SCI leads to severe motor and sensory impairments ${ }^{45}$. Also, about two million and a half people have this disease and the annual rate of new injuries is about 130,000 around the world ${ }^{2}$. Transplanted NSCs has found to improve functional repair in SCI via inducing endogenous repair or by integration of myelinating oligodendrocytes and neuronal differentiation ${ }^{46}$. For instance, they were found that transplanted neurosphere cells that were isolated from rat embryonic spinal cord can improve motor function by generating neurons in-vivo after transplantation in rat spinal cord model. Furthermore, the synaptic structures of neurons were generated following transplantation ${ }^{19}$. Previously, the human foetal NSC gives rise to neuronal cells after implanted into the injured rat spinal cord at nine days following injury ${ }^{47}$. Moreover, another study showed that NSCs can produce neurotrophic factors such as BDNF and NG. For example, NSCs were transplanted in the damaged area of spinal cord in experimental rats and the mechanism of axonal repair following implantation was investigated. It was suggested that NSCs may improve axonal regeneration through neurotrophic factors ${ }^{5}$. Moreover, a previous result showed that the levels of growth factors were markedly raised at $48 \mathrm{~h}$ after transplantation in the spinal cord of mouse ${ }^{20}$. The beneficial effects of NSCs following transplantation encouraged the neurologist and neurosurgeons to translate the preclinical experiments into human clinical trials.

\section{Sources of neural stem cell for transplantation}

NSCs are a subtype of progenitor cells of nervous system that can self-renew by dividing and generate both neurons and glia ${ }^{48}$. They derived from the ganglionic eminence of embryonic CNS and from SVZ and SGZ of adults mammalian brains ${ }^{16 \& 49}$. Moreover, the periventricular tissues of the spinal cord represent addition sources for $\mathrm{NSC}^{50}$. Various studies have found that cells can induce to differentiate into NSCs (Figure 2). These cells have been tested using different protocols and under different neurological conditions. Human embryonic stem cells (hESCs) that obtained from aborted foetuses are one of these important sources ${ }^{51}$. hESCs are pluripotent and differentiated cells and therefore they can be generated any undifferentiated cell in the body including NSCs ${ }^{52 \&, 53}$. Despite these types of stem cells have an excellent potential, their use is restricted or forbidden in several countries due to moral and religious principles in addition to some ethical and practical restrictions accompanied to their clinical application. Moreover, there are several serious problems related to dissecting embryonic materials, homo/heterogeneity of donated materials and viability, the number of brains required for every surgery, immune rejections and their teratoma formation after transplantation ${ }^{49 \& 54}$. Human induced pluripotent stem cells (hiPSCs) is a good tool for the design of cells based therapy technique and less ethical constricted sources of NSCs, they are obtained by reprogramming the somatic stem cell ${ }^{49}$. hiPSC are pluripotent cells that can be differentiated to any cells type $\mathrm{e}^{55}$. Mesenchymal stem cell (MSC) also can differentiate into $\mathrm{NSCs}^{54 \& 56}$. MSC is multipotency and self-renewing cell isolated from different sources like bone marrow and blood $^{53 \& 57}$. 


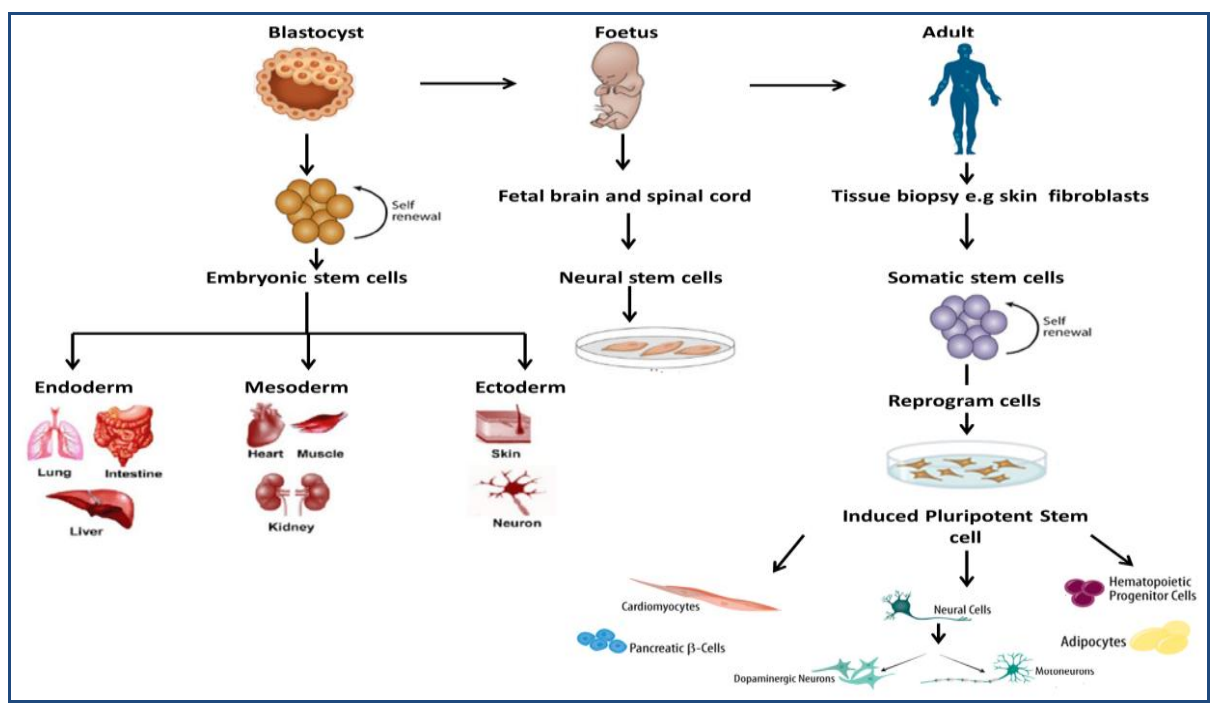

Fig. 2: Schematic illustrations of main sources of NSCs for transplantation. There are three main sources of NSCs: human embryonic stem cells can be isolated from the inner cell mass of a blastocyst, 3-4-month-old foetuses brains which directly harvested then expanded and differentiated to produce NSCs; induced pluripotent stem cells can be derived from the reprogrammed adult somatic stem cells.

\section{NSCs therapy in human clinical trials}

Several studies observe the regenerative effects after NSC transplantation in various neurological diseases by replacing damaged cells and providing neurotrophic factors (Table $1)^{62}$. Therefore, the animal experimental studies translated into human clinical trials to determine safety in neurological disorders patients. For instance, clinical trials were conducted using foetal NSCs for lysosomal storage diseases ${ }^{58-60}$. In advanced stages of Batten's disease, the high dose of NSC can be used safely in children. Also, transplanted NSCs can treat young patients with Pelizaeus Merzbacher disease, a myelination disease that impacts male children. This study showed some neurological improvement in three patients (of four) and the myelination process happened in the white matter region of implantation when compared to sites distant to implantation $^{61}$. Studies by the company ReNeuron have used immortalized human foetal NSCs to treat stroke; they observed no cells-related or immune harmful effects in a phase I trial of 11 patients during 12 months following transplantation. The second phase II study is ongoing to evaluate the advantage of NSCs implants 2-4 months following stroke. This study consists of 41 patients in two separate trial cohorts ${ }^{62}$. Recent trials have been conducted in patients with thoracic and cervical spinal cord injuries by using hNSCs (derived from fetal spinal cord). hNSCs have been expanded in culture before implantation. The initial phase I trials have shown the safe injection in patients with chronic spinal cord injury with no adverse effects 18-27 months post-procedure ${ }^{63}$. Also, one study that did not reach the clinical efficacy required, a phase II trial in patients with cervical spinal cord injury have investigated the safe use of hNSC transplantation following 12 months and showed an increased motor performance in the patients ${ }^{64}$. Also, NSC is in clinical trial for ALS treatment. The company Neuralstem carried out phase I trial for both ambulatory and non-ambulatory ALS patients, 500,000 to 1 million NSCs derived from spinal cord of human foetal were implanted into the lumbar and cervical sites of spinal cord. The finding from this study showed little improvement in survival benefit compared to animal models experiments of ALS show some efficacy of prolonged survival following NSCs implants ${ }^{65-}$ ${ }^{69}$. Interestingly, NSCs are being trialled for SCI repair. The company Stem Cells Inc. conducted a phase I and II clinical trials using foetal NSCs in 12 patients. Twenty million was injected into above and below region of injury. This study observed there are no adverse effects following transplantation and they noted several neurological improvements such as electrophysiological response and a return of minor motor control capacities in some patients $^{62}$. 
Table 1: Clinical trials of neural stem cell in neurological treatment. Table adapted from ${ }^{(62)}$

\begin{tabular}{|c|c|c|c|c|}
\hline $\begin{array}{l}\text { Trial Sponsor } \\
\text { (Location) }\end{array}$ & Disease Target & Cell Therapy & No. Patients & Phase \\
\hline \multirow[t]{3}{*}{$\begin{array}{l}\text { Neuralstem Inc. } \\
\text { (MD, USA) }\end{array}$} & $\begin{array}{l}\text { Amyotrophic lateral } \\
\text { sclerosis }\end{array}$ & $\begin{array}{l}\text { Foetal-derived neural } \\
\text { stem cells }\end{array}$ & 18 & phase I \\
\hline & $\begin{array}{l}\text { Amyotrophic lateral } \\
\text { sclerosis }\end{array}$ & $\begin{array}{l}\text { Foetal-derived neural } \\
\text { stem cells }\end{array}$ & 18 & phase II \\
\hline & $\begin{array}{c}\text { Chronic spinal cord } \\
\text { injury }\end{array}$ & $\begin{array}{l}\text { Foetal-derived neural } \\
\text { stem cells }\end{array}$ & 4 & phase I \\
\hline \multirow[t]{3}{*}{$\begin{array}{l}\text { ReNeuron Ltd. } \\
\text { (UK) }\end{array}$} & Stroke & $\begin{array}{l}\text { Human neural stem } \\
\text { cells }\end{array}$ & 12 & phase I \\
\hline & Stroke & $\begin{array}{l}\text { Human neural stem } \\
\text { cells }\end{array}$ & 41 & phase II \\
\hline & Lower limb ischemia & $\begin{array}{l}\text { Human neural stem } \\
\text { cells }\end{array}$ & 9 & phase I \\
\hline \multirow[t]{5}{*}{$\begin{array}{l}\text { Stem Cells Inc. } \\
\text { (CA, USA) }\end{array}$} & $\begin{array}{l}\text { Neuronal ceroid } \\
\text { lipofuscinosis }\end{array}$ & $\begin{array}{c}\text { Human CNS stem } \\
\text { cells }\end{array}$ & 6 & phase I \\
\hline & $\begin{array}{l}\text { Cervical spinal cord } \\
\text { injury }\end{array}$ & $\begin{array}{c}\text { Human CNS stem } \\
\text { cells }\end{array}$ & 50 & phase II \\
\hline & Macular degeneration & $\begin{array}{c}\text { Human CNS stem } \\
\text { cells }\end{array}$ & 15 & phase I/II \\
\hline & $\begin{array}{c}\text { Thoracic spinal cord } \\
\text { injury }\end{array}$ & $\begin{array}{c}\text { Human CNS stem } \\
\text { cells }\end{array}$ & 12 & phase I/II \\
\hline & $\begin{array}{c}\text { Pelizaeus-Merzbacher } \\
\text { disease }\end{array}$ & $\begin{array}{c}\text { Human CNS stem } \\
\text { cells }\end{array}$ & 4 & phase I \\
\hline $\begin{array}{l}\text { TRANSEURO } \\
\text { (UK) }\end{array}$ & Parkinson's disease & $\begin{array}{c}\text { Foetal-derived } \\
\text { dopaminergic cells }\end{array}$ & 40 & phase I \\
\hline $\begin{array}{l}\text { Wroclaw } \\
\text { Medical } \\
\text { University } \\
\text { (Poland) }\end{array}$ & Spinal cord injury & $\begin{array}{l}\text { Olfactory ensheathing } \\
\text { cells, autologous }\end{array}$ & 10 & phase I \\
\hline
\end{tabular}

\section{Limitations of NSCs-based therapy}

NSCs therapies in neurological regenerative are a distant goal because there are several issues remain to be settled. One of these issues is that high percentage of grafted cells are given rise to astrocyte, but not to neuron or oligodendrocyte ${ }^{19 \& 70}$. Another issue faced in NSC applications is the cells death after implantation. Multiple reports displayed that the increased level cytokines and extracellular glutamate immediately following injury lead to the poor survival of NSCs transplant $^{20,47}$. Also, other obstacles related to NSCs isolation including ethical concerns, immunological rejection and formation of 
teratocarcinoma ${ }^{71 \& 72}$. Also, the activation of microglia is another limitation of cells graft. The brain's resident immune cell (microglia), can proliferate and migrate to injury sites ${ }^{73}$. Microglia can phagocyte toxic substances and cellular debris which have an reduction impact on neuronal axon and generate proinflammatory cytokines including IL-1, IL-6, nitric oxide and chemokines into the damaged $\operatorname{area}^{73-76}$. Several experiments have shown that microglia cause permanent neurological deficits because they can make neurotoxic molecules $^{75}$. The microglia surround and phagocyte the injected cells ${ }^{20 \& 78}$. An in vitro experiment investigates the direct influences of microglia on NSC. The activation of microglia leads to a high level of pro-inflammatory cytokines resulting in an increase in NSC apoptosis and a decrease in their neuronal differentiation ${ }^{79}$. Also, the activated microglia may affect neurogenesis and myelination ${ }^{80 \& 81}$. NSCs received great interest because of their therapeutic effects on neurological diseases. Therefore, extensive ongoing researches carried out to improve the therapeutic efficacy of the NSCs.

\section{Conclusion}

NSCs are a great therapeutic approach for neurological repair. NSCs can replace the damaged neural tissue. In addition, this cell has the ability to produce different growth factors that can regenerate and protect hurt tissue. Although, great efforts and progress in cells implantation, the match between human trails and preclinical models remains uncertain. The main aim of translational researchers and clinicians in the field of stem cell therapy for the treatment of nervous system diseases/injuries is to progress stem cell delivery into human clinical trials. Therefore, more studies are necessary to evaluate the feasibility and safety of NSCs implantation and to assess their benefits effects, administration periods, adjusting doses, safety, and to choose the best sources of NSCs. Also, the precise mechanisms of action underlying the therapeutic efficacy of stem cells have not been sufficiently explored and still unclear. For this reason, more researches will require to be carefully addressed to investigate the exact mechanism underpinning stem cells therapy. Number ongoing clinical trials provide new hope for future NSCs transplantation. It is the most important to shed light on the combinatory therapies because NSC implantation alone may not be sufficient therapeutic approaches to completely treat the neurological injuries/disease. Therefore, combinatory therapies such as immunosuppressive and anti-inflammatory drugs are necessary for the treatment of such diseases.

\section{Abbreviation}

AD, Alzheimer's disease; ALS, Amyotrophic lateral sclerosis; BDNF, Brain derived neurotrophic factor; CNS, Central nervous system; hESCs, Human embryonic stem cells; hiPSC; Human induced pluripotent stem cell; HD, Huntington's disease; MSCs, Mesenchymal stem cells; MS, Multiple sclerosis; NSCs, Neural stem cells; PD, Parkinson's disease; SCI, Spinal cord injury; SGZ, Subgranular zone; SVZ, Subventricular zone; TBI, Traumatic brain injury.

\section{REFERENCES}

1. O. Lindvall and Z..Kokaia, "Stem cells for the treatment of neurological disorders", Nature, 441, 1094-1096 (2006).

2. S.Thuret, L.D. Moon and F.H. Gage,"Therapeutic interventions after spinal cord injury", Nat Rev Neurosci, 7, 628-643 (2006).

3. X. Chen, Y.Gan Y, Li W, J. Su, Y. Zhang, Y. Huang, A. Roberts, Y. Han, J. Li, Y. Wang and Y. Shi, "The interaction between mesenchymal stem cells and steroids during inflammation", Cell Death Dis, 5, 1-12 (2014).

4. S.K. Vishwakarma, A. Bardia, S.K.Tiwari, S.A. Paspala and A.A. Khan, "Current concept in neural regeneration research: NSCs isolation, characterization and transplantation in various neurodegenerative diseases and stroke: A review", J Adv Res, 5, 277-294 (2014).

5. N. Kamei, N. Tanaka, Y. Oishi, T. Hamasaki, K. Nakanishi, N.Sakai and M. Ochi," BDNF, NT-3, and NGF released from transplanted neural progenitor cells promote corticospinal axon growth in organotypic cocultures", Spine, 32, 12721278 (2007). 
6. R.S. Al-Mayyahi, L.D. Sterio, J.B. Connolly, C.F.Adams, W. A.G. AlTumah, J.Sen, R.D. Emes, S.R. Hart and D.M. Chari, " A proteomic investigation into mechanisms underpinning corticosteroid effects on neural stem cells", Mol Cell Neurosci, 86, 30-40 (2018).

7. S.Casarosa, Y. Bozzi, L. Conti, "Neural stem cells: ready for therapeutic applications", Mol Cell Ther, 2(1), 31 (2014).

8. E.T.da Fonseca, A.C.F. Mançanares, C.E. Ambrósio and M.A.Miglino, "Review point on neural stem cells and neurogenic areas of the central nervous system", Open J Anim Sci, 3(3), 242-247 (2013).

9. N. Dai, and V. Sottile, "Neural Stem Cell Approaches to CNS Repair", Electron J Biol, 4, 79-87 (2008).

10. L. Hao, Z. Zou, H. Tian,Y. Zhang, H. Zhou and L. Liu, "Stem cell-based therapies for ischemic stroke", Biomed Res Int, Article ID 468748 (2014).

11. S. Qin, "Endothelial cells stimulate selfrenewal and expand neurogenesis of neural stem cells", Science, 304, 13381340 (2004).

12. G.C. Bellenchi, F.Volpicelli, V.Piscopo, C.Perrone -Capano, and U.di Porzio, "Adult neural stem cells: an endogenous tool to repair brain injury?", $J$ Neurochem, 124, 159-167 (2013).

13. O. Lindvall and Z. Kokaia, "Stem cells for the treatment of neurological disorders", Nature, 441(7097), 1094-1096 (2006).

14. A. Björklund, S.B. Dunnett, P. Brundin, A.J. Stoessl, C.R. Freed, R.E. Breeze, M. Levivier, M. Peschanski, L.Studer and R.Barker, "Neural transplantation for the treatment of Parkinson's disease", Lancet Neurol, 2, 437-445 (2003).

15. J. Imitola, K.Raddassi, K.I.Park, F.J.Mueller, M. Nieto, Y.D. Teng, D. Frenkel, J. Li, R.L.Sidman, C.A. Walsh and E.Y.Snyder, "Directed migration of neural stem cells to sites of CNS injury by the stromal cell-derived factor $1 \alpha / \mathrm{CXC}$ chemokine receptor 4 pathway", Proc Natl Acad Sci, 101,18117-18122 (2004).

16. G .Martino, S.Pluchino, "The therapeutic potential of neural stem cells", Nat Rev Neurosci, 7, 395-406 (2006).
17. S. Louis, C. Mak and B. Reynolds, "Methods to Culture, Differentiate, and Characterize Neural Stem Cells from the Adult and Embryonic Mouse Central Nervous System", Methods Mol Biol, 946, 163-79 (2013).

18. R. S. Al-Mayyahi, "An investigation of the mechanisms underpinning the effect of anti-inflammatory drugs on neural stem cells", Keele University, 2017.

19. Y. Ogawa, K. Sawamoto, T. Miyata, S. Miyao, M. Watanabe, M. Nakamura, B.S. Bregman, M. Koike, Y. Uchiyama, Y.Toyama and H. Okano, "Transplantation of in vitro-expanded fetal neural progenitor cells results in neurogenesis and functional recovery after spinal cord contusion injury in adult rats", J Neurosci Res, 69, 925-933(2002).

20. D. Bottai, L. Madaschi, A.M. Di Giulio and A. Gorio, "Viability-dependent promoting action of adult neural precursors in spinal cord injury", Molecular Medicine, 14, 634-644 (2008).

21. S. Pluchino, A. Quattrini, E. Brambilla, A. Gritti, G. Salani, G. Dina, R. Galli, U. Del Carro, S. Amadio, A. Bergami and R. Furlan, "Injection of adult neurospheres induces recovery in a chronic model of multiple sclerosis", Nature, 422(6933), 688-694 (2003).

22. C. Wang, C.F. Lu, J. Peng, C.D. Hu and Y. Wang, "Roles of neural stem cells in the repair of peripheral nerve injury", Neural Regen Res, 12, 2106-2112 (2017).

23. Y. Ke, L. Chi, R. Xu, C. Luo, D. Gozal and R. Liu, "Early response of endogenous adult neural progenitor cells to acute spinal cord injury in mice", Stem Cells, 24, 1011-9 (2006).

24. J. Dietrich and G. Kempermann, "Role of Endogenous Neural Stem Cells in Neurological Disease and Brain Repair Neural Stem Cells in the Mammalian CNS", Brain repair, 557, 191-220 (2006).

25. Z. Kokaia, P. Thored, A. Arvidsson and O.Lindvall, "Regulation of stroke-induced neurogenesis in adult brain-recent scientific progress", Cereb Cortex, 16,162-1676 (2006).

26. A. Arvidsson, T. Collin, D. Kirik, Z. Kokaia and O. Lindvall, "Neuronal 
replacement from endogenous precursors in the adult brain after stroke", Nat Med, 8, 963-970 (2002).

27. O . Lindvall and Z. Kokaia, "Stem cells in human neurodegenerative disorders time for clinical translation", J Clin Invest, 120, 299 (2010).

28. A. Arvidsson, T. Collin, D. Kirik, Z. Kokaia and O. Lindvall, "Neuronal replacement from endogenous precursors in the adult", Nat Med, 9, 54-553 (2003).

29. N. Kaneko, E. Kako and K. Sawamoto, "Prospects and limitations of using endogenous neural stem cells for brain regeneration", Genes (Basel), 2, 107130(2011).

30. B.Winner, Z. Kohl and F.H. Gage, "Adult neurogenesis and neurodegenerative disease", Regen Med, 33, 1139-1151 (2011).

31. J. E. Burda and M.V. Sofroniew, "Reactive gliosis and the multicellular response to CNS damage and disease", Neuron, 81, 229-248 (2014).

32. G. Ming and H. Song, "Adult Neurogenesis in the Mammalian Central Nervous System", Annu Rev Neurosci, 28, 223-250 (2005).

33. Y. Uyanikgil and H.A. Balcioglu, "Neural stem cell therapy in neurological diseases", Arch Med Sci, 5, 296-302 (2009).

34. K.G.Bath and F.S. Lee, "Neurotrophic factor control of adult SVZ neurogenesis", Dev Neurobiol, 70, 339-349 (2010).

35. Y.Tang, J. Wang, X. Lin, L. Wang, B. Shao, K. Jin, Y. Wang and G.Y. Yang, "Neural stem cell protects aged rat brain from ischemia-reperfusion injury through neurogenesis and angiogenesis", J Cereb Blood Flow Metab, 34, 1138-1147 (2014).

36. S. Ryu, S.H. Lee, S.U. Kim, and B.W. Yoon, "Human neural stem cells promote proliferation of endogenous neural stem cells and enhance angiogenesis in ischemic rat brain", Neural Regen Res, 11, 298-304 (2016).

37. E.W. Baker, S.R. Platt, V.W. Lau, H.E. Grace, S.P. Holmes, L. Wang, K.J. Duberstein, E.W. Howerth, H.A. Kinder, S.L. Stice, and D.C. Hess, "Induced Pluripotent Stem Cell-Derived Neural Stem Cell Therapy Enhances Recovery in an Ischemic Stroke Pig Model", Sci Rep,7, 1-15 (2017).

38. Y. Wang, S.Z. Lin, A.L. Chiou, L.R. Williams and B.J. Hoffer, "Glial Cell Line-Derived Neurotrophic Factor Protects against Ischemia-Induced Injury in the Cerebral Cortex". J Neurosci, 17, 434-4348 (1997).

39. D. E. Redmond, K.B. Bjugstad, Y.D. Teng, V. Ourednik, J. Ourednik, D.R. Wakeman, X.H. Parsons, R. Gonzalez, B.C. Blanchard, S.U. Kim and Z. Gu, "Behavioral improvement in a primate Parkinson's model is associated with multiple homeostatic effects of human neural stem cells", Proc Natl Acad Sci, 104, 12175-12180 (2007).

40. M.S.Cho, Y.E. Lee, J.Y. Kim, S. Chung, Y.H. Cho, D.S. Kim, S.M. Kang, H. Lee, M.H. Kim, J.H. Kim, and J.W.Leem, "Highly efficient and large-scale generation of functional dopamine neurons from human embryonic stem cells", Proc Natl Acad Sci, 105, 33923397 (2008).

41. J. C. Reidling, A. Relaño-Ginés, S.M. Holley, J. Ochaba, C. Moore, B. Fury, A. Lau, A.H. Tran, S. Yeung, D. Salamati and C. Zhu, "Human Neural Stem Cell Transplantation Rescues Functional Deficits in R6/2 and Q140 Huntington's Disease Mice", Stem Cell Reports, 10, 5872 (2018).

42. I. Kerkis, M.S. Haddad, C.W. Valverde and S. Glosman, "Neural and mesenchymal stem cells in animal models of Huntington's disease: Past experiences and future challenges", Stem Cell Res Ther, 14 (6), 232 (2015).

43. A.Vercelli, O.M. Mereuta, D. Garbossa, G. Muraca, K. Mareschi, D. Rustichelli, I. Ferrero, L. Mazzini, E. Madon and F. Fagioli, "Human mesenchymal stem cell transplantation extends survival, improves motor performance and decreases neuroinflammation in mouse model of amyotrophic lateral sclerosis", Neurobiol Dis, 31, 395-405 (2008).

44. S.M. Klein, S. Behrstock, J. McHugh, K. Hoffmann, K.Wallace, M. Suzuki, P. Aebischer and S C.N. vendsen, "GDNF Delivery Using Human Neural Progenitor 
Cells in a Rat Model of ALS", Hum Gene Ther, 16, 509-521 (2005).

45. I. M. Pereira, A. Marote, A.J. Salgado and N.A. Silva, "Filling the Gap: Neural Stem Cells as A Promising Therapy for Spinal Cord Injury", Pharmaceuticals, 12 (2), 65 (2019).

46. M. J. Hooshmand, C.J. Sontag, N. Uchida, S. Tamaki, A.J. Anderson and B.J. Cummings, "Analysis of host-mediated repair mechanisms after human CNS-stem cell transplantation for pinal cord injury: Correlation of engraftment with recovery", PLoS One, 4 (6), e5871 (2009).

47. Y. I. Tarasenko, J. Gao, L. Nie, K.M. Johnson, J.J. Grady, C.E. Hulsebosch, D.J. McAdoo and P. Wu, "Human Fetal Neural Stem Cells Grafted Into Contusion-Injured Rat Spinal Cords Improve Behavior", $\boldsymbol{J}$ Neurosci Res, 85, 47-57 (2007).

48. S. Temple, "The development of neural stem cells", Nature, 414, 1120-117 (2001).

49. C. Grochowski, E. Radzikowska and R. Maciejewski, "Neural stem cell therapyBrief review", Clin Neurol Neurosurg, 173, 8-14 (2018).

50. A. J. Mothe and C.H.Tator, "Review of transplantation of neural stem/progenitor cells for spinal cord injury", Int J Dev Neurosci, 31, 701-713 (2013).

51. S. Pluchino, L. Zanotti, M. Deleidi and G. Martino, "Neural stem cells and their use as therapeutic tool in neurological disorders", Brain Res Rev, 48, 211-219 (2005).

52. F . Ali, S.R.W. Stott and R.A. Barker, "Stem cells and the treatment of Parkinson's disease", Exp Neurol, 260, 311(2014).

53. S. Bajada, I. Mazakova, B. Ashton, J.B. Richardson and N. Ashammakhi, "Stem Cells in Regenerative Medicine", Top Tissue Eng, 4, 1-28 (2008).

54. O. AAD, S. JPB and H. JDC, "Neural Stem Cell Transplantation and Mechanisms for Functional Recovery", $\boldsymbol{J}$ Stem Cell Res Ther, 1, 59-71(2017).

55. S.Yamanaka, "Strategies and New Developments in the Generation of Patient-Specific Pluripotent Stem Cells", Cell Stem Cell, 1, 39-49 (2007).
56. R. Volkman and D.Offen "Concise Review: Mesenchymal Stem Cells in Neurodegenerative Diseases", Stem Cells, 35, 1867-1880(2017).

57. Y.P. Liu, B.T. Lang, M.K. Baskaya, R.J. Dempsey and R. Vemuganti, "The potential of neural stem cells to repair stroke-induced brain damage", Acta Neuropathol, 117, 469-480 (2009).

58. A. Trounson, R.G. Thakar, G. Lomax and D.Gibbons, "Clinical trials for stem cell therapies", BMC Med, 9, 52 (2011).

59. L. S. Shihabuddin and I. Aubert, "Stem cell transplantation for neurometabolic and neurodegenerative diseases", Neuropharmacology, 58, 845-854 (2010).

60. N. R. Selden, A. Al-Uzri, S.L. Huhn, T.K Koch, D.M. Sikora, M.D. Nguyen-Driver, D.J. Guillaume, J.L. Koh, S.H. Gultekin, J.C. Anderson and H.Vogel, "Central nervous system stem cell transplantation for children with neuronal ceroid lipofuscinosis", J Neurosurg Pediatr, 11, 643-652 (2013).

61. N. Gupta, R.G. Henry, J. Strober, S.M. Kang, D.A. Lim, M. Bucci, E. Caverzasi, L. Gaetano, M.L. Mandelli, T. Ryan and R. Perry, "Neural stem cell engraftment and myelination in the human brain", $\mathbf{S c i}$ Transl Med, 4(155), 155ra137 (2012).

62. A .Trounson and C. McDonald, "Stem Cell Therapies in Clinical Trials: Progress and Challenges", Cell Stem Cell, 17, 1122 (2015).

63. E. Curtis, J.R. Martin, B. Gabel, N. Sidhu, T.K. Rzesiewicz, R. Mandeville, S. Van Gorp, M. Leerink, T. Tadokoro, S. Marsala and C. Jamieson, "A first-inhuman, phase I study of neural stem cell transplantation for chronic spinal cord injury", Cell stem cell, 22(6), 941-50 (2018).

64. A. D. Levi, K.D. Anderson, D.O. Okonkwo, P. Park, T.N. Bryce, S.N. Kurpad, B. Aarabi, J. Hsieh and K. Gant, "Clinical outcomes from a multi-center study of human neural stem cell transplantation in chronic cervical spinal cord injury", J neurotrauma,36(6), 891902 (2019).

65. E. L. Feldman, N.M. Boulis, J. Hur, K. Johe, S.B. Rutkove, T. Federici, M. Polak, J. Bordeau, S.A. Sakowski and J.D.Glass, 
"Intraspinal neural stem cell transplantation in amyotrophic lateral sclerosis: phase 1 trial outcomes", Ann Neurol, 75, 363-73 (2014).

66. J. D.Glass, N.M. Boulis, K. Johe, S.B. Rutkove, T. Federici, M. Polak, C. Kelly and E.L. Feldman, "Lumbar Intraspinal Injection of Neural Stem Cells in Patients with Amyotrophic Lateral Sclerosis: Results of a Phase I Trial in 12 Patients", Stem Cells, 30, 1144-1151 (2012).

67. H. J. Lee, K.S. Kim, J. Ahn, H.M. Bae, I. Lim, and S.U.Kim, "Human motor neurons generated from neural stem cells delay clinical onset and prolong life in ALS mouse model", PLoS One, 9, 1-9 (2014).

68. J. Riley, T. Federici, M. Polak, C. Kelly, J. Glass, B. Raore, J. Taub, V. Kesner, E.L. Feldman and N.M. Boulis, "Intraspinal stem cell transplantation in amyotrophic lateral sclerosis: A phase i safety trial, technical note, and lumbar safety outcomes", Neurosurgery, 71, 405-416 (2012).

69. G. M. Thomsen, G. Gowing, S. Svendsen and C.N.Svendsen, "The past, present and future of stem cell clinical trials for ALS", Exp Neurol, 262, 127-137 (2014).

70. S. Wu, Y. Suzuki, M. Kitada, M. Kitaura, K. Kataoka, J. Takahashi, C. Ide and Y. Nishimura, "Migration, integration, and differentiation of hippocampus-derived neurosphere cells after transplantation into injured rat spinal cord", Neurosci Lett, 312, 173-176 (2001).

71. D. Yu, and G. Silva, "Stem cell sources and therapeutic approaches for central nervous system and neural retinal disorders", Neurosurg Focus, 24(3-4), E10 (2008).

72. J. A. Steinbeck and L. Studer, "Moving stem cells to the clinic: Potential and limitations for brain repair", Neuron, 86, 187-206 (2015).

73. T. M. Tikka and J.E. Koistinaho, "Minocycline provides neuroprotection against N-methyl-D-aspartate neurotoxicity by inhibiting microglia", $\boldsymbol{J}$ Immunol, 166, 7527-7533 (2001).
74. J. E. Merrill, L.J. Ignarro, M.P. Sherman, J. Melinek and T.E.Lane, "Microglial cell cytotoxicity of oligodendrocytes is mediated through nitric oxide", $\boldsymbol{J}$ Immunol, 151, 2132-2141(1993).

75. J. A. Smith, A. Das, S.K. Ray and N.L. Banik, "Role of pro-inflammatory cytokines released from microglia in neurodegenerative diseases", Brain Res Bull, 87, 10-20 (2012).

76. C. C. Chao, S. Hu, K. Close, C.S. Choi, T.W. Molitor, W.J. Novick and P.K. Peterson, "Cytokine release from microglia: differential inhibition by pentoxifylline and dexamethasone", $\boldsymbol{J}$ Infec Dis, 166 (4), 847-853(1992)..

77. B. W. Festoff, S. Ameenuddin, P. M. Arnold, A. Wong, K.S. Santacruz and B.A.Citron, "Minocycline neuroprotects, reduces microgliosis, and inhibits caspase protease expression early after spinal cord injury", J Neurochem, 97, 1314-1326 (2006).

78. H. Su, T.H. Chu and W. Wu, "Lithium enhances proliferation and neuronal differentiation of neural progenitor cells in vitro and after transplantation into the adult rat spinal cord", Exp Neurol, 206, 296-307 (2007).

79. E. Cacci, M.A. Ajmone-Cat, T. Anelli, S. Biagioni and L. Minghetti, "In Vitro Neuronal and Glial Differentiation from Embryonic or Adult Neural Precursor Cells are Differently Affected by Chronic or Acute Activation of Microglia", Glia, 56(4), 412-425 (2008).

80. A. Bosco, D.M. Inman, M.R. Steele, G. Wu, I. Soto, N. Marsh-Armstrong, W.C. Hubbard, D.J. Calkins, P.J. Horner and M.L.Vetter, "Reduced retina microglial activation and improved optic nerve integrity with minocycline treatment in the DBA/2J mouse model of glaucoma", Investig Ophthalmol Vis Sci, 49, 14371446 (2008).

81. C. T. Ekdahl, J. H. Claasen, S. Bonde, Z. Kokaia and O. Lindvall, "Inflammation is detrimental for neurogenesis in adult brain", Proc Natl Acad Sci, 100, 13632136379 (2003). 


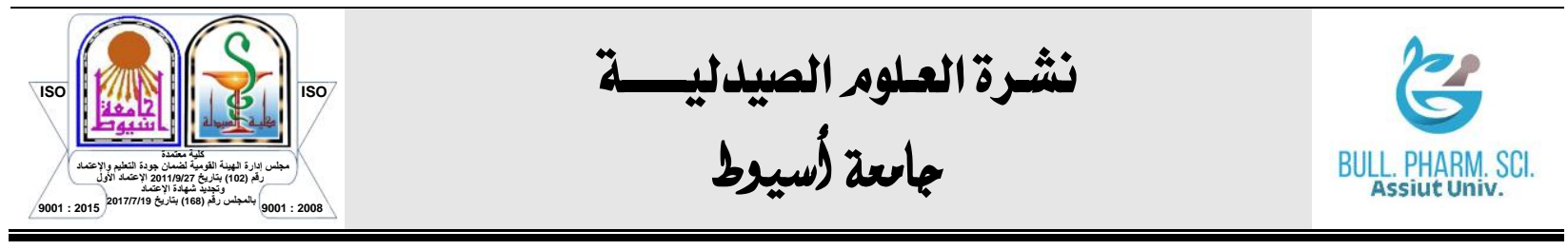

\section{الخلايا الجذعية العصبية كنهج علاجي واعد في الأمر اض العصبية رواء سالم المياحي}

$$
\text { فرع العلوم المختبرية السريرية ، كلية الصيدلة ، جامعة البصرة ، البصرة ، العراق }
$$

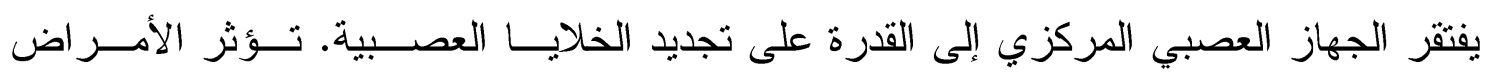

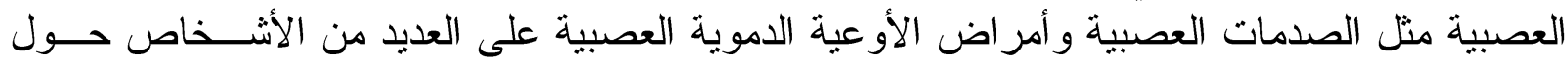

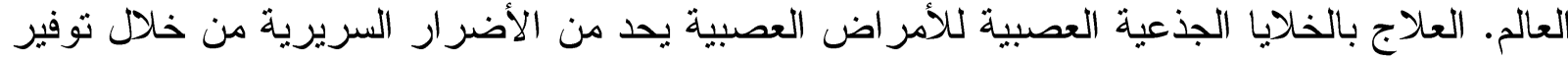

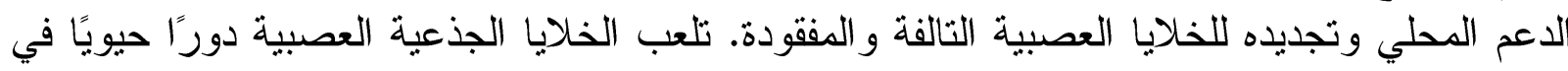

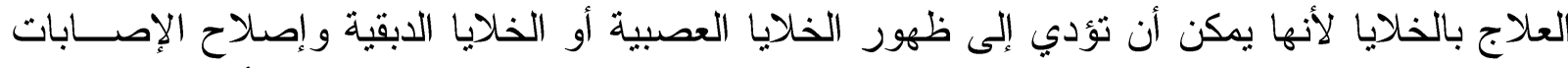

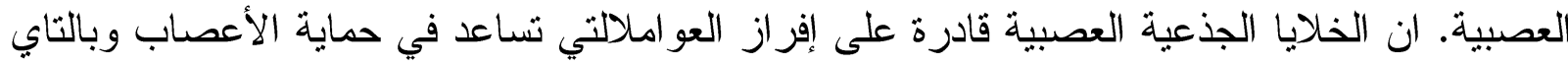

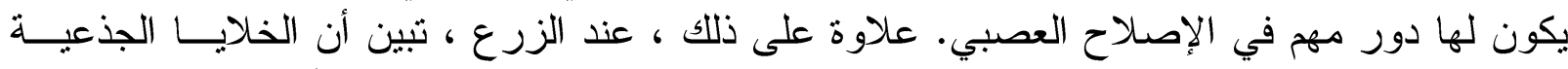

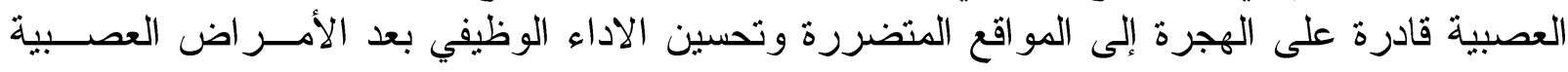

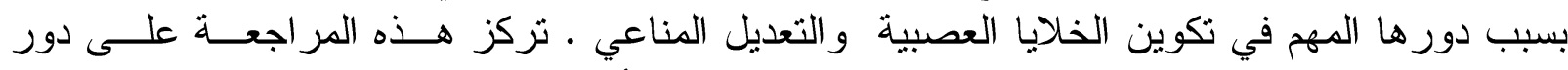

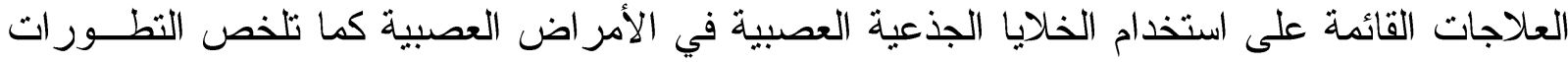

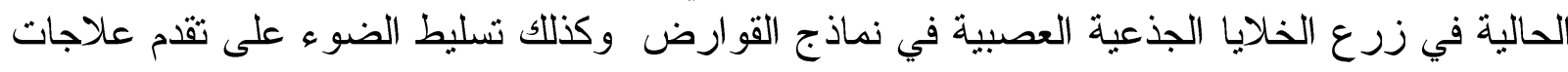
الخلايا الجذعية العصبية في التجارب السريزية التهرية. 